\title{
Control of inventory system with random demand and product damage during delivery using the linear quadratic gaussian method
}

Sutrisno, Widowati, R. Heru Tjahjana

Department of Mathematics, Diponegoro University, Indonesia

\section{Article Info}

Article history:

Received Mar 13, 2020

Revised Mar 4, 2021

Accepted Mar 28, 2021

\section{Keywords:}

Inventory system

Linear quadratic gaussian

Product damage

Random demand

Supply chain management

\begin{abstract}
This study formulates a dynamical system for the control of a single product inventory system in accordance with the random value of demand and the percentage of damaged product during the delivery process. The formulated model has the form of a linear state-space system comprising of two disturbances, which represents the random value of demand and the percentage of the damaged product during delivery. The optimal value of the product amount ordered to the supplier is properly calculated by using the linear quadratic gaussian (LQG) method. The controller is used by the manager to make inventory level decisions under the uncertainty of demand and damaged items during the product delivery process. The result showed that the optimal product order for each review time was achieved, and the inventory level was used to obtain the right set point properly. Moreover, based on comparison with other research results, the proposed model was well performed.
\end{abstract}

This is an open access article under the CC BY-SA license.

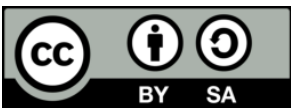

Corresponding Author:

Sutrisno

Department of Mathematics

Diponegoro University

Prof. Soedarto St., Tembalang, Semarang 50275, Indonesia

Email: s.sutrisno@live.undip.ac.id

\section{INTRODUCTION}

A supply chain comprises of many parties that need to be properly managed and optimized to minimize cost and maximize profits. Over the past few decades, various studies have been conducted on supply chain optimization, which indicates peoples' interest in topics related to the product's flow process. Many purposes can be addressed to the studies associated with the supply chain, such as maintaining operational costs [1]. Some existing managerial topics related to supply chains were conducted using specific pre-existing cases such as the control of an inventory system with deteriorating stock [2], transportation losses [3], time delay [1], and random demand [4]. However, there are limited studies related to inventory control problems on the use of both random demand and possibility of products to be damaged during shipping.

According to research, suppliers, manufacturers, and distributors in the supply chain have an inventory system used to stock their raw material or products for future usage. Products stored in warehouses require holding costs to pay. In the other hand, the warehouse and suppliers' capacity need to be considered while storing products. Therefore, the number of products stored in the warehouse needs to be optimized. This is commonly known as inventory management, with several approaches previously constructed as the decisionmaking tool to solve this problem. Each approach comprises of some specific characteristics associated with the problem faced. Several approaches used the mathematical model to describe the behavior of the problem. 
However, the simplest dynamical model for the inventory system was developed using a linear state space equation [5]. Some more advanced approaches were also developed using a price discount [6]-[8]. Further works were carried out for specific control purposes such as on-hand stock tracking by using some existing control algorithm like $H_{\infty}$ method [9], linear quadratic controller (LGQ) [10], and predictive controller [11].

Numerous studies have also been conducted on the optimal control of a dynamic system using various methods with their advantages and disadvantages available in the literature. One of the methods used to solve optimization problems with uncertain parameters is the linear quadratic gaussian (LQG) [12]. There are several reports in varying fields regarding the advantages of using this control method: for example, power system [13], [14], mechanical control problem [15], [16], power flow [17], unmanned aerial vehicle [18], simplified car [19], acquisition process [20], slung transportation [21], vehicle automation [22], [23], buck converter controlling [24], robotic \& electronic systems [25], [26], and optics system [27].

Simulations are needed to be carried out to determine the performance of a control method for a specific dynamical system. Therefore, this study employed the LQG method to inventory dynamical systems to determine the optimal decisions for a single product inventory system with uncertain demands and product damages during delivery. This control aims to decide the optimal amount of the product that needs to be ordered to the supplier, where the inventory level is controlled to follow a set-point or trajectory. In the discussed inventory model, there is an uncertain parameter representing the percentage of the ordered product, which cannot enter the warehouse due to damage during the delivery process. Therefore, to observe this control method's performance, computational simulations were carried out and compared to some existing literature results.

\section{RESEARCH METHOD}

\subsection{Dynamical system}

In an inventory system with one product type stored in the warehouse, the numbers of items are observed periodically, for instance, daily is known as the review time period. Let $k \in \mathrm{N}$ be the review time, where $y(k) \geq 0$ the inventory level i.e., the number of items stored in the warehouse at review time $k, d(k)$ is the number of the products demanded at review time $k$ which is uncertain and is treated as a disturbance of the system, and $u(k)$ is the number of items ordered to the supplier at review time $k$. In the problem discussed here, the ordered product at review time $k$ does not enter the warehouse at the same review time $k$. However, there is a possibility of a time gap between ordering and receiving items. This time gap, also known as delay time, is denoted by $\bar{n} \in \mathrm{N}$. This means that the items ordered at review time $k$ arrives the warehouse at review time $k+\bar{n}$.

In particular, not all items ordered to the supplier are received due to damages incurred during delivery. Let $u_{d}(k)$ be the number of damaged items from the total amount of the ordered products at review time $k$. This value is not known with certainty; therefore, it is treated as the disturbance of the system. The control problem is associated with selecting the number of items that need to be ordered to the supplier at every review time to ensure the on-hand product stock level follows a set point or trajectory. Let $y(k<0)=$ 0 , then the evolution of the inventory level $y$ for any review time $k \geq 0$ is expressed as follows:

$$
\begin{gathered}
y(k)=u(0)-u_{d}(0)+u(1)-u_{d}(1)+\cdots+u(k-\bar{n}-1)-u_{d}(k-\bar{n}-1)-d(0)-d(1)-d(2)-\cdots \\
-d(k-1)
\end{gathered}
$$

this can also be rewritten as follows:

$$
y(k)=\sum_{j=0}^{k-\bar{n}-1} u(j)-\sum_{j=0}^{k-\bar{n}-1} u_{d}(j)-\sum_{j=0}^{k-1} d(j)
$$

Taken: $=\bar{n}+1, y(k)=: x_{1}(k)$, and $x_{i}(k):=u(k-\bar{n}+i)$ for $i=2,3, \ldots, \bar{n}+1$. The (1) can also be rewritten as follows:

$$
\left\{\begin{aligned}
x(k+1) & =A x(k)+B_{1} u(k)+B_{2} u_{d}(k) \\
y(k) & =C x(k)-d(k)
\end{aligned}\right.
$$

where $x(k)=\left[x_{1}(k), x_{2}(k), \ldots, x_{n}(k)\right]^{\top}$ is used to denote the state vector,

$$
A=\left[\begin{array}{ccccc}
1 & 1 & 0 & \cdots & 0 \\
0 & 0 & 1 & \cdots & 0 \\
0 & 0 & 0 & \cdots & \vdots \\
\vdots & \vdots & \vdots & \ddots & 1 \\
0 & 0 & 0 & \cdots & 0
\end{array}\right], B_{1}=\left[\begin{array}{c}
0 \\
0 \\
\vdots \\
1
\end{array}\right], B_{2}=\left[\begin{array}{c}
-1 \\
0 \\
\vdots \\
0
\end{array}\right], C=[1,0,0, \cdots, 0]
$$


are constant matrices. This is a linear state space equation with two disturbances i.e., $u_{d}(k)$ and $d(k)$. Many control methods are suitable to control this class of system. We choose the LQG as it is a simply control method and is available in many software/applications.

\subsection{LQG (revisiting)}

Consider a linear dynamical inventory system with disturbance in the form of (2) where $u_{d}(k)$ and $d(k)$ used to denote white noise with covariance matrix;

$$
\left.E\left[\begin{array}{c}
u_{d}(k) \\
d(k)
\end{array}\right]\left[u_{d}(k) \quad d(k)\right]\right]=\operatorname{diag}\left[E\left[u_{d}(k) u_{d}^{\top}(k)\right], E\left[d(k) d^{\top}(k)\right]\right]>0 .
$$

This dynamical system is used for regulation purposes; i.e., the control input value is used to bring the state value to the origin. The objective function is as follows:

$$
J=x^{\top}(N) F x(N)+\sum_{k=0}^{N-1}\left(\|x(k)\|_{Q(k)}^{2}+\|u(k)\|_{R(k)}^{2}\right)
$$

subject to (2), with constant weighting matrices $F \geq 0, Q(k) \geq 0$ and $R(k) \geq 0$. This control method works by minimizing the expectation of this objective function using the following feedback form:

$$
u(k)=-K(k) \hat{x}(k)
$$

where,

$$
\begin{gathered}
\hat{x}(k+1)=A \hat{x}(k)+B u(k)+L(k+1) y(k+1)-L(k+1) C A \hat{x}(k)+L(k+1) C B u(k), \\
K(k)=\left(B^{\top} S(k+1) B+R(k)\right)^{-1} B^{\top} S(k+1) A,
\end{gathered}
$$

and $L(k)=P(k) C^{\top}\left(C P(k) C^{\top}+D(k)\right)^{-1}$. The optimal input value is iteratively determined from the following matrix equations:

$$
\begin{gathered}
P(k+1)=\left\{A P(k) A^{\top}-A P(k) C^{\top}\left(C P(k) C^{\top}+D(k)\right)^{-1} C P(k) A^{\top}\right\}, \\
P(0)=E\left[(x(0)-\hat{x}(0))(x(0)-\hat{x}(0))^{\top}\right], \\
S(k)=A^{\top} S(k+1) A-A^{\top} S(k+1) B\left(B^{\top} S(k+1) B+R\right)^{-1} B^{\top} S(k+1) A+Q(k)
\end{gathered}
$$

using initial value $\hat{x}(0)=E[x(0)]$ and $S(N)=F$.

\section{NUMERICAL EXPERIMENT}

In an inventory model (2) with a one-day review and delay time of $\bar{n}=1$, the dynamical model is derived as follows:

$$
\begin{gathered}
x(k+1)=\left[\begin{array}{ll}
1 & 1 \\
0 & 0
\end{array}\right] x(k)+\left[\begin{array}{l}
0 \\
1
\end{array}\right] u(k)+\left[\begin{array}{c}
-1 \\
0
\end{array}\right] u_{d}(k), \\
y(k)=\left[\begin{array}{ll}
1 & 0
\end{array}\right] x(k)-d(k) .
\end{gathered}
$$

The value of the parameters used in this simulation is summarized in Table 1, with the inventory system and the corresponding controller simulated and calculated using MATLAB and a computer with $3.2 \mathrm{GHz}$ of Quad-core Processor and 8 GB of memory.

Table 1. Parameter value for numerical experiment

\begin{tabular}{cccccccccc}
\hline Parameter & $Q$ & $R$ & $F$ & $u_{\min }$ & $u_{\max }$ & $y_{\min }$ & $y_{\max }$ & $E\left(u_{d}(k) u_{d}^{\prime}(k)\right)$ & $E\left(d(k) d^{\top}(k)\right)$ \\
\hline Value & $\operatorname{diag}[0.1,0.1]$ & 1 & 0 & 0 & 200 & 0 & 300 & $\operatorname{diag}[1,0]$ & 1 \\
\hline
\end{tabular}

Figure 1 shows the demand value that was randomly generated by using a normal distribution with mean and variance values of 20 and 10 units for a 30-days review time, and zero demand towards day 50 . The same scenario is applied to the review time from day 51 to 100 . The purpose of the 0 valued demand is to show the controller's response and the corresponding output (inventory level) for this scenario. Figure 2 displays the number of products that need to be procured by the supplier. For review times above day 30, the numbers of procured products are decided by the controller following the demand value, as shown in Figure 1. The result 
showed that after day 30, the demand value was 0 units till day 50. Therefore, the controller decided to make 0 units for the product order, with a similar explanation applied for review time up to day 100 .

Figure 3 shows the system's inventory level as the consequences of the decision illustrated in Figure 2. The number of products stored in the warehouse fluctuated to day 30 in order to satisfy demand and gain minimal objective function. For then, till day 50, the inventory level approached the set point with the difference between units 1 and 0 . A similar explanation is applied from day 51 to 100, which shows that the demand is constant with the inventory level properly set to a point. A different behavior appeared when the demand is unknown, with the inventory level fluctuated to satisfy the demand. The controller works with each review time to bring the inventory level as close as possible to the set point. However, a sudden occurrence in demand decreases the products stored in the inventory at the current review time, thereby, making the level far from the set point.

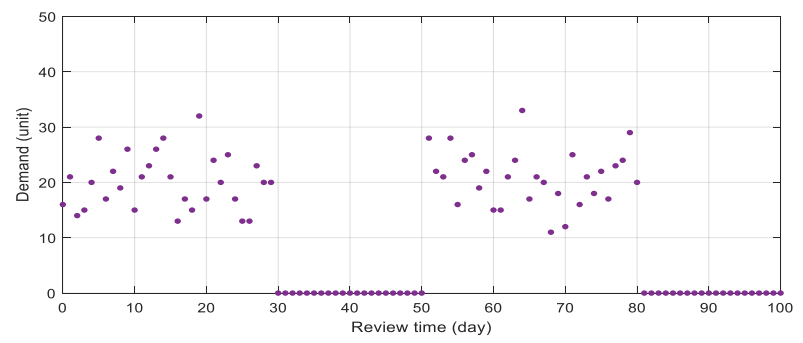

Figure 1. Random demand value

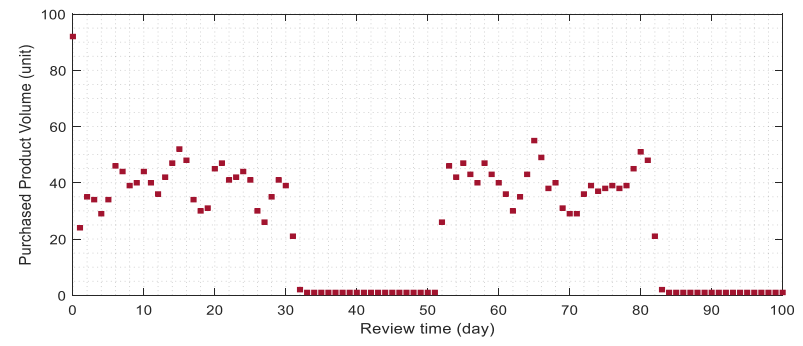

Figure 2. The optimal number of products ordered to the supplier

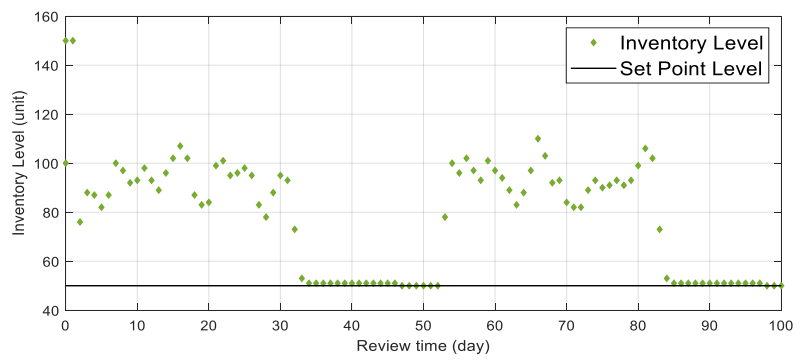

Figure 3. Inventory level and its set point

The results shown in Figures 1 to 3 are similar to available previous studies and used for verification. The set point tracking result shown in Figure 3, for the review time of 0 to 30 and 55 to 85 were located at 80 to 100 units and far from the set point of 50 units. Compared to the on-hand stock level dynamics shown in Figures 2 and 3 in [28], [29], it shows that this phenomenon is proper due to the controller ability to satisfy uncertain demands. For review time from day 30 to 50 and day 80 to 100, the inventory level is closed to the set point as shown in Figure 2 in [30], [11]. The review time between day 30 and 33 or 80 and 83, with a set point of 0 , shows that the inventory level was not directly at 0 . This is due to the delivery delay when the ordered product fails to directly enter the warehouse, which means that the controller needs time to bring the inventory level to the set point. This result is better compared to the stock level dynamic shown in the results discussed in [9] due to the shorter gap time of the inventory level to be near the set point. 


\section{CONCLUDING REMARKS AND FUTURE RESEARCH DIRECTION}

This study analyzed an optimal control problem of a single product inventory system with random demand and damages incurred during delivery. The controller was designed using the LQG method, where the demand value and the damaged product during the delivery process were treated as disturbances in the dynamical model. The applied controller was given strong performance based on the numerical experiment and by comparing it with some existing works. This means that practitioners can use this result as a decision-making tool to solve inventory control problems.

Further studies are interesting for multi-product and multi-supplier cases. In addition, more complicated inventory problems such as inventory systems with deteriorating products and shortages are also interesting to study. This will produce a more complicated dynamical system and therefore it needs a study to find a suitable control method.

\section{ACKNOWLEDGMENTS}

DRPM RISTEK-BRIN Republic of Indonesia funded this research under the PDUPT research grant contract no. 225-96 UN7.6.1/PP/2020.

\section{REFERENCES}

[1] P. Ignaciuk, "Discrete inventory control in systems with perishable goods - A time-delay system perspective," IET Control Theory Appl., vol. 8, no. 1, pp. 11-21, 2014, doi: 10.1049/iet-cta.2013.0636.

[2] P. Ignaciuk, "Control of production-inventory systems with deteriorating stock and unreliable delayed supply channel," Proc. IEEE Conf. Decis. Control, 2013, pp. 306-311, doi: 10.1109/CDC.2013.6759899.

[3] A. Bartoszewicz and M. Maciejewski, "Dead-beat sliding mode control of perishable inventories with transportation losses and multiple suppliers," 2013 Eur. Control Conf. ECC 2013, 2013, pp. 3209-3215, doi: 10.23919/ECC.2013.6669170.

[4] Sutrisno, Widowati, and R. H. Tjahjana, "Single Product Inventory Control Considering Unknown Demand Using Linear Quadratic Gaussian," 2018 IEEE International Conference on Robotics, Biomimetics, and Intelligent Computational Systems (Robionetics), 2018, pp. 17-20, doi: 10.1109/ROBIONETICS.2018.8674677.

[5] P. Ignaciuk and A. Bartoszewicz, "Linear-quadratic optimal control strategy for periodic-review inventory systems," Automatica, vol. 46, no. 12, pp. 1982-1993, 2010, doi: 10.1016/j.automatica.2010.09.010.

[6] Sutrisno, Widowati and D. A. Munawwaroh, "Hybrid mathematical model of inventory system with piecewise holding cost and its optimal strategy, "2015 International Conference on Advanced Mechatronics, Intelligent Manufacture, and Industrial Automation (ICAMIMIA), 2015, pp. 29-33, doi: 10.1109/ICAMIMIA.2015.7507996.

[7] Widowati, R. H. Tjahjana, and Sutrisno, "Joint decision on integrated supplier selection and stock control of inventory system considering purchase discount," Int. J. Supply Chain Manag., vol. 6, no. 4, pp. 61-69, 2017.

[8] S. M. Mousavi, S. T. A. Niaki, A. Bahreininejad, and S. N. Musa, "Multi-Item Multiperiodic Inventory Control Problem with Variable Demand and Discounts: A Particle Swarm Optimization Algorithm," Sci. World J., vol. 2014, 2014. doi: 10.1155/2014/136047.

[9] C. Yang, B. Zhang, L. Wei and Y. Zhao, "Hoo tracking control for periodic-review inventory systems, "2016 35th Chinese Control Conference (CCC), 2016, pp. 2510-2514, doi: 10.1109/ChiCC.2016.7553741.

[10] Sutrisno, Widowati and R. H. Tjahiana, "Application of Robust Linear Quadratic Control for Inventory System with Unknown Demand: Single Product Case," 2018 2nd International Conference on Informatics and Computational Sciences (ICICoS), 2018, pp. 1-5, doi: 10.1109/ICICOS.2018.8621666.

[11] S. Sutrisno, W. Widowati and R. H. Tjahjana, "Robust Predictive Control Application and Simulation of Inventory Controlling with Imperfect Delivery Process, "2019 International Conference on Information and Communications Technology (ICOIACT), 2019, pp. 639-642, doi: 10.1109/ICOIACT46704.2019.8938536.

[12] M. Green and D. J. N. Limebeer, Linear Robust Control, vol. 31, no. 11. London: Prentice Hall, 1995.

[13] M. Bhadu, N. Senroy, I. N. Kar, and G. N. Sudha, "Robust linear quadratic Gaussian-based discrete mode wide area power system damping controller," IET Gener. Transm. Distrib., vol. 10, no. 6, pp. 1470-1478, 2016, doi: 10.1049/iet-gtd.2015.1113.

[14] D. Yu, Y. Mao, B. Gu, S. Nojavan, K. Jermsittiparsert, and M. Nasseri, "A new LQG optimal control strategy applied on a hybrid wind turbine/solid oxide fuel cell/ in the presence of the interval uncertainties," Sustain. Energy, Grids Networks, vol. 21, no. 100296, pp. 1-9, 2020, doi: 10.1016/j.segan.2019.100296.

[15] A. Niragire, R. Abdulkader and R. A. McCann, "Linear quadratic Gaussian control for resonance damping in microgrids with cascaded converters, "2017 IEEE Power \& Energy Society Innovative Smart Grid Technologies Conference (ISGT), 2017, pp. 1-5, doi: 10.1109/ISGT.2017.8086017.

[16] A. Kalbat, "Linear Quadratic Gaussian (LQG) Control of wind turbines, "2013 3rd International Conference on Electric Power and Energy Conversion Systems, 2013, pp. 1-5, doi: 10.1109/EPECS.2013.6713053.

[17] A. Al-Digs, S. V. Dhople and Y. C. Chen, "Linear-quadratic-Gaussian control of line active-power flow, "2017 IEEE Power \& Energy Society General Meeting, 2017, pp. 1-5, doi: 10.1109/PESGM.2017.8274725.

[18] Umm-e-Aimen and M. Liaquat, "Fault tolerant tracking control of Unmanned Aerial Vehicle using Linear Quadratic Gaussian with integral reconfiguration control, "2017 International Automatic Control Conference (CACS), 2017, pp. 1-4, doi: 10.1109/CACS.2017.8284243. 
[19] S. Diemer and S. Bonnabel, "An invariant Linear Quadratic Gaussian controller for a simplified car, "2015 IEEE International Conference on Robotics and Automation (ICRA), 2015, pp. 448-453, doi: 10.1109/ICRA.2015.7139037.

[20] T. A. Weber and V. A. Nguyen, "A linear-quadratic Gaussian approach to dynamic information acquisition," Eur. J. Oper. Res., vol. 270, no. 1, pp. 260-281, 2018, doi: 10.1016/j.ejor.2018.03.003.

[21] H. I. Lee et al., "Parameter-robust linear quadratic Gaussian technique for multi-agent slung load transportation," Aerosp. Sci. Technol., vol. 71, pp. 119-127, 2017, doi: 10.1016/j.ast.2017.09.014.

[22] A. P. Nandakumar, L. Seban, R. J. Abraham and M. V. Dhekane, "LQG Controller for Load Relief in theCombined Rigid Body and Flexibility Model of a Launch Vehicle," 2019 2nd International Conference on Intelligent Computing, Instrumentation and Control Technologies (ICICICT), 2019, pp. 781-786, doi: 10.1109/ICICICT46008.2019.8993277.

[23] S. Jeon, K. Lee, H. Kim and D. Kum, "Path Tracking Control of Autonomous Vehicles Using Augmented LQG with Curvature Disturbance Model, "2019 19th International Conference on Control, Automation and Systems (ICCAS), 2019, pp. 1543-1548, doi: 10.23919/ICCAS47443.2019.8971654.

[24] M. Almaged, S. I. Khather, A. I. Abdulla and M. R. Amjed, "Comparative Study of LQR, LQG and PI Controller Based on Genetic Algorithm Optimization for Buck Converters," 2019 11th International Conference on Electrical and Electronics Engineering (ELECO), 2019, pp. 1012-1017, doi: 10.23919/ELECO47770.2019.8990572.

[25] J. Dabbagh and I. H. Altas, "Nonlinear Two-Wheeled Self-Balancing Robot Control Using LQR and LQG Controllers," 2019 11th International Conference on Electrical and Electronics Engineering (ELECO), 2019, pp. 855-859, doi: 10.23919/ELECO47770.2019.8990610.

[26] L. Castro, L. Cunha, B. Dutra and A. Silveira, "Digital LQG Controller Design Applied to an Electronic System," IEEE Latin America Transactions, vol. 18, no. 03, pp. 581-588, March 2020, doi: 10.1109/TLA.2020.9082730.

[27] J. Wang, Y. Guo, L. Kong, and C. Rao, "Experimental demonstration of LQG control with disturbance mitigation on multiple modes in adaptive optics system," Optik, vol. 202, pp. 1-9, 2020, doi: 10.1016/j.ijleo.2019.163594.

[28] Y. Akikuni, K. Okuhara and Y. Fujisaki, "Optimal control of inventory systems with multiple suppliers," 2017 56th Annual Conference of the Society of Instrument and Control Engineers of Japan (SICE), 2017, pp. 353-354, doi: 10.23919/SICE.2017.8105757.

[29] Sutrisno, Widowati and R. H. Tjahiana, "Application of Robust Linear Quadratic Control for Inventory System with Unknown Demand: Single Product Case," 2018 2nd International Conference on Informatics and Computational Sciences (ICICoS), 2018, pp. 1-5, doi: 10.1109/ICICOS.2018.8621666.

[30] N. N. Nandola and D. E. Rivera, "An Improved Formulation of Hybrid Model Predictive Control with Application to Production-Inventory Systems," IEEE Transactions on Control Systems Technology, vol. 21, no. 1, pp. 121-135, 2013, doi: 10.1109/TCST.2011.2177525.

\section{BIOGRAPHIES OF AUTHORS}
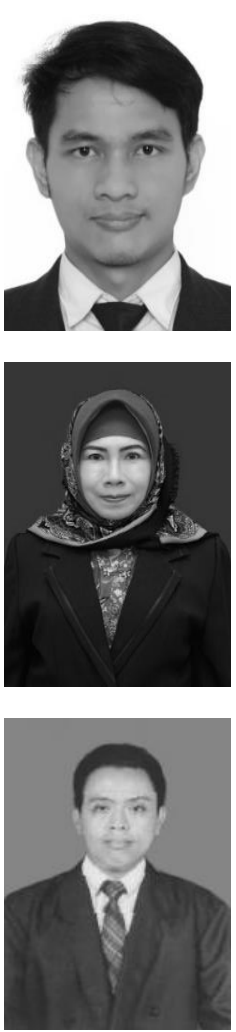

Sutrisno is a lecturer and researcher at the Department of Mathematics, Diponegoro University, Indonesia with Master of Science degree obtained from Universitas Gadjah Mada (Indonesia) in 2012. He obtained Bachelor degree in Mathematics from Universitas Diponegoro (Indonesia) in 2009. His researches are in fields of mathematical modeling, system \& control, and optimization both in theory and applications. Further info can be found on his homepage: http://math.fsm.undip.ac.id/sutrisno.

Widowati is a professor at the Department of Mathematics, Diponegoro University, Indonesia. She obtained doctorate degree from Institut Teknologi Bandung (Indonesia) in 2005. Her researches are in fields of mathematical modeling, system \& control, both in theory and applications. Further info can be found on her homepage: http://math.fsm.undip.ac.id/widowati

R. Heru Tjahjana is a lecturer and researcher at the Department of Mathematics, Diponegoro University, Indonesia. He obtained doctorate degree from Institut Teknologi Bandung (Indonesia) in 2010. His researches are in fields of mathematical modeling, system \& control, both in theory and applications. Further info can be found on his homepage: http://math.fsm.undip.ac.id/rherutjahjana. 